SILVA MG; SHARMA RD; JUNQUEIRA AMR; OLIVEIRA CM. 2006. Efeito da solarização, adubação química e orgânica no controle de nematóides em alface sob cultivo protegido. Horticultura Brasileira 24: 489-494.

\title{
Efeito da solarização, adubação química e orgânica no controle de nematóides em alface sob cultivo protegido ${ }^{1}$
}

\author{
Marlene G da Silva ${ }^{2}$; Ravi D Sharma ${ }^{3}$; Ana Maria R Junqueira ${ }^{2}$; Charles M de Oliveira ${ }^{3}$ \\ ${ }^{2}$ UnB-FAV, C. Postal 4508, 70910-970 Brasília-DF; ${ }^{3}$ Embrapa Cerrados, C. Postal 08223, 73310-970 Planaltina-DF; E-mail: \\ lelenegs@yahoo.com.br; anamaria@unb.br.
}

\section{RESUMO}

Os efeitos da solarização do solo associados à adubação no controle de nematóides e na produtividade da alface cultivar "Verônica" foram avaliados em solo naturalmente infestado. Dois experimentos foram conduzidos, um com e outro sem solarização, em casa de vegetação, ambos com cinco tratamentos: adubação orgânica; nitrogênio na forma amoniacal $\left(\mathrm{NH}_{4}\right)$; adubação com NPK; adubação orgânica mais NPK; testemunha (sem adubação). No experimento solarizado, o solo foi coberto durante 132 dias com filme plástico transparente. A população de nematóides foi avaliada em duas camadas $(0-10 \mathrm{~cm}$ e $10-20 \mathrm{~cm})$, e as coletas de solo foram feitas em três épocas (antes da implantação do experimento; após a solarização; após a colheita). O delineamento experimental foi o de blocos ao acaso com três repetições em parcelas sub-subdivididas, com medidas no espaço e no tempo (5 adubações x 2 camadas x 3 épocas), e a comparação entre experimentos foi feita pela análise conjunta. $\mathrm{O}$ efeito da solarização sobre o controle de nematóides dependeu da adubação e camada do solo. A solarização reduziu a população de nematóides na camada de $0-10 \mathrm{~cm}$ em todos os tratamentos de adubação. A solarização associada ao $\mathrm{NH}_{4}$ reduziu a diversidade na camada de 10-20 cm. A solarização combinada às adubações orgânica, N-NH , NPK e orgânica mais NPK reduziu de maneira eficiente o número de galhas, o número de massas de ovos e a população de nematóides fitoparasitas nas raízes, em especial de Meloidogyne spp. Solarização combinada à adubação orgânica apresenta potencial para controle de nematóides e redução do uso de agrotóxicos.

Palavras-chave: Lactuca sativa L., Meloidogyne spp., energia solar, tratamento térmico do solo.

\begin{abstract}
Effect of solarization, chemical and organic fertilization on the control of nematode on greenhouse lettuce

The effect of soil solarization and fertilization was evaluated for nematode control in 'Veronica' lettuce in naturally infested soil. The two greenhouse experiments consisted of five fertilization treatments: organic fertilization; ammoniacal nitrogen (ammonium sulphate); NPK fertilization; organic and NPK fertilization; control (without fertilization), in solarized and non-solarized soils. In the solarized plot the soil was covered during 132 days with transparent plastic film. The nematode populations were evaluated in two layers $(0-10$ $\mathrm{cm}$ and $10-20 \mathrm{~cm}$ ) with soil collections done at three times (before solarization; after solarization; and after harvest). The experimental design was of sub-subdivided blocks plots with assessments in space and time ( 5 fertilization $\mathrm{x} 2$ depths $\mathrm{x} 3$ times). The effect of solarization on nematode control was dependent on fertilization and soil depth. Solarization reduced nematodes population at $0-10 \mathrm{~cm}$ depth in all the fertilization treatments. Solarization associated to ammoniacal nitrogen reduced nematode diversity at $10-20 \mathrm{~cm}$ depth. Solarization associated to organic, ammoniacal nitrogen, NPK and organic + NPK fertilization reduced efficiently gall numbers, egg masses number and phytoparasitic nematodes, specially Meloidogyne spp., in lettuce roots. Solarization associated to organic fertilization has a potential to be used in nematode control and to reduce pesticides application.
\end{abstract}

Keywords: Lactuca sativa L, Meloidogyne sp., solar energy, soil thermal treatment.

\section{(Recebido para publicação em 15 de março de 2006; aceito em 18 de dezembro de 2006)}

\begin{abstract}
$\mathrm{A}$ alface (Lactuca sativa L.) está sujeita à ocorrência de diversas doenças, entre elas as meloidoginoses, sendo as espécies Meloidogyne incognita (Kofoid e White) Chitwood e Meloidogyne javanica (Treub) Chitwood as mais importantes (Netscher \& Sikora, 1990).

Em cultivo protegido existem poucas opções de métodos economicamente viáveis para o controle de Meloidogyne spp. após o seu estabelecimento (Vida et al., 2004). O controle
\end{abstract}

de nematóides pode ser efetuado por meio de nematicidas e rotação de culturas, entre outras medidas. A primeira pode provocar desequilíbrio biológico e deixar resíduos nos vegetais, solo e água, além de onerar os custos de produção. A segunda, embora eficiente, pode ter uso limitado, uma vez que as culturas utilizadas na rotação podem não proporcionar o devido retorno econômico ou podem elevar a população de algum nematóide secundário, além do alto custo do espaço utilizado (Ribeiro et al.,
1998). Medidas alternativas, como a incorporação de compostos orgânicos, vêm sendo estudadas (RodriguesKábana, 1986), uma vez que a densidade populacional desses fitopatógenos pode ser reduzida e a tolerância da planta aumentada (Ribeiro et al., 1998), além da adição de nutrientes e melhorias na estrutura do solo proporcionadas por essa prática.

A solarização, que consiste na cobertura do solo úmido em pré-plantio, com um filme transparente de

${ }^{1}$ Parte da Dissertação de Mestrado apresentada pela primeira autora ao curso de pós graduação em Ciências Agrárias da UnB-FAV. Trabalho parcialmente financiado pela CAPES 
polietileno durante a época de intensa radiação solar, tem se mostrado como uma alternativa viável aos métodos químicos para desinfestação do solo para o controle de fitopatógenos e plantas daninhas, especialmente em hortaliças e plantas ornamentais, (Ghini, 2004). Esse método tem mostrado eficácia no controle de nematóides, por efeitos diretos, causados pelas altas temperaturas, e indiretos, favorecendo o controle biológico e, consequentemente, a supressividade do solo (Souza, 2004). A solarização tem possibilitado reduções de 42 a $100 \%$ na população dos seguintes gêneros de nematóides: Meloidogyne, Heterodera, Globodera, Pratylenchus, Ditylenchus, Paratrichodorus, Criconemella, Xiphinema, Helicotylenchus e Paratylenchus (Stapleton \& Devay, 1986). Entretanto, em alguns casos a solarização não apresentou controle eficiente de galhas radiculares causadas por Meloidogyne spp. em cenoura cultivada em solo arenoso (Marenco \& Lustosa, 2000) e M. arenaria em tomate, por afetar microorganismos antagonistas (Freitas et al., 2000).

A aplicação de material orgânico no solo tem a propriedade de atuar de forma benéfica na população de microrganismos antagonistas, incrementando a produção de substâncias tóxicas aos fitopatógenos e aumentando a supressividade (Souza, 2004). Entretanto, esta prática isoladamente tem sido pouco efetiva no controle de muitas doenças, pois implica na perda por volatilização de substâncias resultantes da decomposição do material com efetiva ação tóxica aos fitopatógenos (Stapleton, 2000). A combinação da solarização com a adição de compostos orgânicos tem um potencial significativo no controle de fitopatógenos e aumento da produtividade das culturas (Ricci et al., 2000; Hasing et al., 2004). Essa nova condição propicia a degradação acelerada do material, levando à produção de compostos tóxicos no solo (Souza, 2004), pois o efeito conjunto e cumulativo desses compostos e da temperatura sob o plástico possuem ação letal sobre os nematóides (Bettiol et al., 1996; Ostrec \& Grubsic, 2003; Baptista et al., 2004 e Souza, 2004). Ao término do processo, ocorre a redução na população de patógenos, proporcionando um novo equilíbrio da biota, aumentando assim a supressão e tornando mais lenta a reinfestação (Souza, 2004).

O objetivo deste trabalho foi avaliar a eficiência da solarização associada à adubação química e orgânica, no controle de nematóides na cultura da alface sob cultivo protegido.

\section{MATERIAL E MÉTODOS}

O trabalho foi conduzido em casa de vegetação na Fazenda Água Limpa (FAL), estação experimental da Universidade de Brasília (UnB), localizada em Brasília, DF (latitude 1556'00" S; longitude: 5756'00" W; altitude 1080m, clima tropical de altitude). O solo é do tipo Latossolo Vermelho Amarelo, textura argilosa, tendo sido anteriormente cultivado com alface, apresentando ocorrência natural de Meloidogyne spp. Para melhor avaliação dos efeitos dos tratamentos, foi utilizada a cultivar de alface Verônica, suscetível aos nematóides das galhas.

A casa de vegetação de $70 \mathrm{~m}^{2}$ foi dividida em duas partes, onde foram implantados dois experimentos, um com solarização e outro sem solarização. Em cada experimento, nas parcelas de $1,0 \mathrm{~m}$ x $1,8 \mathrm{~m}$, foram implantados os seguintes tratamentos de adubação: adubação orgânica (T1); nitrogênio na forma amoniacal (sulfato de amônio) (T2); adubação com NPK, de acordo com a análise de solo (T3); adubação orgânica mais NPK (T4); Testemunha (sem adubação) (T5). Antes da colocação do plástico em 01/09/2004, o solo foi preparado por aração e gradagem, e irrigado até atingir a capacidade de campo. Os tratamentos T1, T2, e T4 foram adubados respectivamente com $5,4 \mathrm{~kg}$ de esterco bovino, $135 \mathrm{~g}$ de sulfato de amônio e 5,4kg de esterco bovino.

Visando evitar efeito de borda, a solarização foi realizada em toda a área do experimento solarizado durante 132 dias (24/09/2004 a 02/02/2005) utilizando-se uma lona plástica transparente de polietileno, de $150 \mu$ de espessura. Em 10/02/2005, após a retirada do plástico, foi feita a adubação das parcelas, em pré-plantio com as respectivas doses:
$\mathrm{T} 1=5,4 \mathrm{~kg}$ de esterco bovino; $\mathrm{T} 2=60 \mathrm{~g}$ de superfosfato simples $\left(10,8 \mathrm{~g}\right.$ de $\left.\mathrm{P}_{2} \mathrm{O}_{5}\right)$ e $12 \mathrm{~g}$ de cloreto de potássio $\left(7,2 \mathrm{~g} \mathrm{~K}_{2} \mathrm{O}\right)$; $\mathrm{T} 3=27 \mathrm{~g}$ de sulfato de amônio $(5,4 \mathrm{~g}$ de $\mathrm{N}), 60 \mathrm{~g}$ de superfosfato simples $(10,8 \mathrm{~g}$ de $\left.\mathrm{P}_{2} \mathrm{O}_{5}\right)$ e $12 \mathrm{~g}$ de cloreto de potássio $\left(7,2 \mathrm{~g} \mathrm{~K}_{2} \mathrm{O}\right) ; \mathrm{T} 4=27 \mathrm{~g}$ de sulfato de amônio $(5,4 \mathrm{~g}$ de $\mathrm{N}), 60 \mathrm{~g}$ de superfosfato simples $\left(10,8 \mathrm{~g}\right.$ de $\left.\mathrm{P}_{2} \mathrm{O}_{5}\right)$ e $12 \mathrm{~g}$ de cloreto de potássio $\left(7,2 \mathrm{~g} \mathrm{~K}_{2} \mathrm{O}\right)$ e $5,4 \mathrm{~kg}$ de esterco bovino; T5= sem adubação. As mudas de alface com 20 dias foram transplantadas em 15/02/2005, com espaçamento de $0,25 \mathrm{~m}$ entre linhas e entre plantas, totalizando 21 plantas por parcela.

As adubações de cobertura em cada tratamento foram realizadas em 28/02/ 2005 (aos 15 dias) e em 18/03/2005 (aos 30 dias), aplicando-se em cada tratamento as seguintes doses: $\mathrm{T} 1=500 \mathrm{~g}$ de esterco bovino; $\mathrm{T} 2=72 \mathrm{~g}$ de sulfato de amônio e $12 \mathrm{~g}$ de cloreto de potássio; $\mathrm{T} 3=72 \mathrm{~g}$ de sulfato de amônio e $12 \mathrm{~g}$ de cloreto de potássio; $\mathrm{T} 4=6 \mathrm{~g}$ de cloreto de potássio, $36 \mathrm{~g}$ de sulfato de amônio e $250 \mathrm{~g}$ de esterco bovino; T5= sem adubação. Foram coletadas amostras de solo compostas (5 subamostras) nas camadas de $0-10 \mathrm{~cm}$ e $10-20 \mathrm{~cm}$ em cada parcela, com um trado holandês, em três épocas: $\left.1^{\text {a }}\right)$ antes da solarização (27/08/ 2004); $\left.2^{a}\right)$ logo após a solarização (02/ $02 / 2005)$; e $3^{a}$ ) no final do ciclo da alface $(30 / 03 / 2005)$. As amostras foram homogeneizadas antes de se extrair $50 \mathrm{~g}$ de solo para isolamento de nematóides, segundo o método modificado de Coolen (1979), uma combinação do método de peneiramento, decantação, centrifugação e flutuação (Sharma, 1985).

Cinco plantas dentro da área útil de cada parcela foram cortadas ao nível do solo para determinação da massa da matéria fresca da parte aérea. O sistema radicular dessas plantas foi colhido para determinação da massa da matéria fresca e da densidade populacional dos nematóides. Para facilitar a visualização das massas de ovos de Meloidogyne spp., foi realizada coloração das raízes com floxina B, (Taylor \& Sasser, 1978). Após a contagem das massas de ovos, os sistemas radiculares foram processados segundo Sharma (1985) para determinação da população de nematóides (ovos, fêmeas jovens, machos, juvenis 
de diferentes estádios). A população de nematóides foi contada utilizando lâmina de Peter em microscópio ótico. A preparação de configurações perineais para a identificação de espécies de Meloidogyne foi feita segundo Hartman \& Sasser (1985), com modificações.

Utilizou-se um delineamento em blocos ao acaso com três repetições em parcelas sub-subdivididas (5 adubações x 2 camadas x 3 épocas). As avaliações foram repetidas no espaço e no tempo, sendo consideradas como parcelas, em cada experimento, os cinco tratamentos de adubação, como sub-parcelas, as duas camadas dentro de cada parcela e como sub-sub-parcelas as três épocas de coleta de amostras. Foram analisadas as variáveis: abundância total (número de nematóides expresso por $\mathrm{kg}$ de solo); diversidade $(\mathrm{d}=(\mathrm{S}-1) / \log \mathrm{N})$, onde $\mathrm{S}$ é o número de gêneros e $\mathrm{N}$, o número de indivíduos de cada amostra (Magurran, 1988); fitoparasitas e saprófitas (número de nematóides fitoparasitas e saprófitas expresso por kg de solo), sendo que, com exceção da variável diversidade, as demais variáveis foram transformadas em $\sqrt{x+0,5}$. A comparação entre os experimentos foi feita pela análise conjunta de experimentos, conforme Campos (1984).

As variáveis número de galhas por sistema radicular (NG), número de massas de ovos por sistema radicular (NMO), população final de Meloidogyne spp. [somatório dos nematóides do solo nas camadas de 0$10 \mathrm{~cm}$ e $10-20 \mathrm{~cm}$ da terceira coleta mais a população de adultos e número de ovos nas raízes] (Pf), massa da matéria fresca da raiz (MMFR) e massa da matéria fresca da parte aérea (MMFPA) foram analisadas apenas na terceira época (colheita) em cada experimento, sendo neste caso, utilizado o delineamento de blocos ao acaso com três repetições, uma vez que não havia o efeito de épocas ou camadas. Da mesma forma, a comparação entre os experimentos foi feita com base na análise conjunta (Campos, 1984), sendo essas variáveis correlacionadas (correlações de Pearson). Para todas as análises estatísticas foram utilizados os aplicativos SAEG5 e Excel. Os dados de número de galhas e número de massas de ovos foram transformados

Tabela 1. Médias de abundância total de nematóides e de nematóides saprófitas por kg de solo na época 2 (após a solarização), para as condições com e sem solarização. Brasília, UnB-FAV, 2005

\begin{tabular}{lcccc}
\hline \multirow{2}{*}{ Experimento } & \multicolumn{2}{c}{ Abundância total $/ \mathbf{~ k g ~ d e ~ s o l o ~}$} & \multicolumn{2}{c}{ Saprófitas $/ \mathbf{~ k g ~ d e ~ s o l o ~}$} \\
\cline { 2 - 5 } & $\mathbf{0 - 1 0} \mathbf{~ m ~}$ & $\mathbf{1 0 - 2 0 ~} \mathbf{~ m}$ & $\mathbf{0 - 1 0 ~ c m}$ & $\mathbf{1 0 - 2 0 ~} \mathbf{~ m}$ \\
\hline Com solarização & $174 \mathrm{~b}$ & $269 \mathrm{a}$ & $88 \mathrm{~b}$ & $118 \mathrm{a}$ \\
Sem solarização & $318 \mathrm{a}$ & $225 \mathrm{a}$ & $175 \mathrm{a}$ & $96 \mathrm{a}$ \\
\hline
\end{tabular}

Valores seguidos por letras diferentes na mesma coluna diferem estatisticamente pelo teste de Tukey ao nível de significância de 5\%. Médias de três repetições. Os dados foram transformados em $\sqrt{x+0,5}$ para análise de variância.

Tabela 2. Médias de diversidade de nematóides em cada tratamento de adubação para as camadas 0-10 cm e 10-20 cm na época da colheita, nos experimentos com solarização e sem solarização. Brasília, UnB-FAV, 2005

\begin{tabular}{lccccc}
\hline Experimento & Orgânica & N-NH4 & NPK & Org. + NPK Testemunha \\
\hline Com solarização & 2,19 a & 2,72 a & 2,31 a & 2,76 a & 3,0 a \\
Sem solarização & 2,65 a & 2,50 a & 3,36 a & 3,01 a & 3,0 a \\
\hline \multicolumn{5}{c}{ Camada 10-20 cm } \\
\hline Com solarização & 2,61 a & $2,41 \mathrm{~b}$ & $3,00 \mathrm{a}$ & 2,68 a & 2,75 a \\
Sem solarização & 2,27 a & 3,52 a & $2,63 \mathrm{a}$ & 3,34 a & 2,55 a \\
\hline
\end{tabular}

Valores seguidos por letras diferentes na mesma coluna em cada adubação e dentro de cada camada diferem estatisticamente pelo teste de Tukey ao nível de significância de 5\%. Médias de três repetições.

em $\sqrt{x+0,5}$ e população final em $\log$ $(\mathrm{x}+1)$ para análise de variância, sendo as médias comparadas pelos testes de Tukey e Scott-Knott a $5 \%$.

\section{RESULTADOS E DISCUSSÃO}

Foram identificados nove gêneros de nematóides (Meloidogyne, Pratylenchus, Helicotylenchus, Criconemella, Paratrichodorus, Aphelenchoides, Aphelenchus, Tylenchus, Ditylenchus), sendo esse número o mesmo na condição com solarização e sem solarização. Os gêneros Trichodorus e Criconema estiveram ausentes na condição com solarização e sem solarização, respectivamente. O gênero Meloidogyne não foi encontrado na segunda época (logo após a solarização) em ambas as condições, com exceção do tratamento adubação orgânica mais NPK na camada $10-20$ cm na condição com solarização.

Diferenças na abundância total foram observadas antes da implantação do experimento e após a solarização. Considerando que, na primeira época de avaliação ainda não haviam sido implantados os tratamentos, os resultados re- fletem apenas a variabilidade inicial da distribuição dos nematóides no solo, a qual segundo Tihohod (1993), é irregular e depende de vários fatores, como culturas anteriores, práticas culturais e comportamento inerente à espécie do nematóide. Sendo assim, havia maior abundância total na camada $0-10 \mathrm{~cm}$ onde posteriormente foi implantado o tratamento $\mathrm{T} 1$ do experimento com solarização comparado ao T1 sem solarização (respectivamente 8.165 e 1.880 nematóides $\mathrm{kg}^{-1}$ de solo), sendo observado o mesmo comportamento para a população de saprófitas (respectivamente 7.034 e 1.183 nematóides $\mathrm{kg}^{-1}$ de solo). Por outro lado, havia maior população de fitoparasitas onde posteriormente foi implantado o tratamento T1 comparado ao T3, (respectivamente 675 e 293 nematóides $\mathrm{kg}^{-1}$ de solo) considerando-se as duas camadas avaliadas.

$\mathrm{Na}$ época 2, a solarização reduziu a população de nematóides na camada 0$10 \mathrm{~cm}$, sendo o mesmo observado para a população de saprófitas (Tabela 1), comprovando que o efeito da elevação da temperatura promovido pela solarização é maior próximo da superfície do solo (Lefèvre \& Souza, 1993). 
Tabela 3. Médias do número de galhas por sistema radicular, número de massas de ovos por sistema radicular, massa da matéria fresca da raiz e massa da matéria fresca da parte aérea para os tratamentos nos experimentos com solarização e sem solarização. Brasília, UnB-FAV, 2005.

\begin{tabular}{|c|c|c|c|c|c|c|c|c|}
\hline \multirow[t]{2}{*}{ Adubação } & \multicolumn{2}{|c|}{ Galhas ( $\left.n^{\circ} s\right)$} & \multicolumn{2}{|c|}{ Massa Ovos ( $\left.n^{\circ} s\right)$} & \multicolumn{2}{|c|}{ M. Fresca Raiz (g/planta) } & \multicolumn{2}{|c|}{$\begin{array}{c}\text { M. Fresca Parte Áerea } \\
\text { (g/planta) }\end{array}$} \\
\hline & Solar & NSol. & Solar & NSol. & Solar & NSol. & Solar & NSol. \\
\hline Orgânica & $3 \mathrm{Bb}$ & $48 \mathrm{Aa}$ & $2 \mathrm{Bb}$ & $35 \mathrm{Aa}$ & $23,8 \mathrm{Aa}$ & $20,9 \mathrm{Aa}$ & $168,5 \mathrm{Aa}$ & $121,9 \mathrm{Ba}$ \\
\hline $\mathrm{N}-\mathrm{NH}_{4}$ & $9 \mathrm{Bb}$ & $148 \mathrm{Aa}$ & $4 \mathrm{Bb}$ & $112 \mathrm{Aa}$ & $20,7 \mathrm{Aa}$ & $27,5 \mathrm{Aa}$ & $225,2 \mathrm{Aa}$ & $182,6 \mathrm{Aa}$ \\
\hline NPK & $28 \mathrm{Bb}$ & $120 \mathrm{Aa}$ & $15 \mathrm{Bb}$ & $119 \mathrm{Aa}$ & $18,1 \mathrm{Aa}$ & $28,9 \mathrm{Aa}$ & $195,7 \mathrm{Aa}$ & $216,0 \mathrm{Aa}$ \\
\hline Org.+ NPK & $5 \mathrm{Bb}$ & $132 \mathrm{Aa}$ & $3 \mathrm{Bb}$ & $110 \mathrm{Aa}$ & $21,2 \mathrm{Aa}$ & $21,7 \mathrm{Aa}$ & $290,7 \mathrm{Aa}$ & $255,1 \mathrm{Aa}$ \\
\hline Test. & $250 \mathrm{Aa}$ & $97 \mathrm{Ab}$ & $184 \mathrm{Aa}$ & $70 \mathrm{Ab}$ & $27,1 \mathrm{Aa}$ & $19,2 \mathrm{Aa}$ & $190,7 \mathrm{Aa}$ & $93,2 \mathrm{Bb}$ \\
\hline
\end{tabular}

Valores seguidos por letras maiúsculas diferentes na mesma coluna diferem estatisticamente pelo teste de Scott-Knott ao nível de significância de 5\%. Valores seguidos por letras minúsculas diferentes na mesma linha, em cada variável, diferem estatisticamente pelo teste de $\mathrm{F}$ (níveis de significância na Tabela 1.12). Médias de três repetições. Dados das variáveis NG "número de galhas" e NMO "número de massas de ovos" foram transformados em $\sqrt{x+0,5}$.

Na época 3 (colheita), a solarização diminuiu a diversidade de nematóides apenas no tratamento de adubação com nitrogênio amoniacal $\left(\mathrm{N}-\mathrm{NH}_{4}\right)$ na camada 10-20 cm (Tabela 2). Os gêneros Helicotylenchus, Aphelenchoides e Tylenchus não foram detectados no tratamento $\mathrm{N}_{-} \mathrm{NH}_{4}$ após a solarização, estando, entretanto, presentes no experimento sem solarização, sugerindo que o efeito do gás amônia $\left(\mathrm{NH}_{3}\right)$, liberado a partir da transformação do amônio $\left(\mathrm{NH}_{4}\right)$ no solo, pode afetar a população de nematóides de maneira seletiva, embora Rodríguez-Kábana (1986) considere que adubações nitrogenadas promovam efeito supressivo na população de nematóides como um todo. Na época 3 (colheita), em todas as parcelas, foram encontradas quatro espécies do gênero Meloidogyne (M. javanica, M.incognita, M. arenaria e M. hapla).

Houve interação significativa entre adubação e solarização indicando que o efeito da solarização depende da adubação do solo. A solarização reduziu o número de galhas e o número de massas de ovos em todos os tratamentos adubados, comportamento inverso ao observado na testemunha (sem adubação) (Tabela 3), demonstrando efeito supressivo da adubação associada à solarização (Ricci et al., 2000). Os tratamentos com adubação orgânica, orgâ-

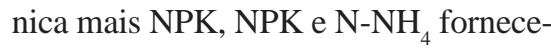
ram $\mathrm{N}$ ao solo, o que pode ter causado este efeito. Os resultados obtidos, com exceção da testemunha, são contrários aos observados por Freitas et al. (2000), que relataram que a solarização, associada ou não à adubação orgânica, não reduziu o número de galhas causado por $M$. arenaria nas raízes de tomate na Flórida. O mesmo foi relatado por Marenco \& Lustosa (2000), que verificaram que a solarização do solo por nove semanas foi ineficiente para controle de Meloidogyne spp. na cultura de cenoura. Entretanto, a redução no número de galhas nos tratamentos solarizados e adubados está de acordo com Rodríguez-Kábana (1986), que afirma ser a adubação química nitrogenada ou orgânica supressora da população de nematóides por favorecer antagonistas ou liberar substâncias tóxicas. Bettiol et al. (1996) verificaram que a solarização do solo por 139 dias com ou sem acréscimo de resíduo orgânico promoveu a redução do número de galhas por planta de forma semelhante ao brometo de metila e concluíram que a solarização do solo foi eficaz no controle de $M$. javanica em quiabeiro. Da mesma forma, Baptista et al. (2004) observaram a diminuição da formação de galhas radiculares de $M$. incognita nos solos solarizados por 63 dias na cultura do tomate em Brasília-DF. Junqueira et al. (2000) utilizaram a solarização por 60 dias, e constaram uma redução significativa no índice médio de infecção por nematóides nas raízes da alface. Baptista et al. (2006) constataram que a solarização e o uso de cama de frangos foram tão eficientes quanto o brometo de metila na redução da população de nematóides e número de massas de ovos nas raízes de tomate.

$\mathrm{Na}$ época da colheita, a população final de nematóides não sofreu influência dos tratamentos de adubação nos dois experimentos. Entretanto, constatou-se interação significativa entre adubação x solarização. Houve redução significativa na população final de Meloidogyne apenas no tratamento com adubação orgânica e na testemunha (Figura 1). Efeito benéfico da solarização na redução de nematóides de galhas também já foram relatados em outros estudos (Bettiol et al., 1996; Baptista et al., 2004; 2006).

Ostrec \& Grubisic (2003) observaram efeito semelhante para Meloidogyne spp. na cultura da alface em solo solarizado em casa de vegetação na Croácia. Greco et al. (1992) constataram que a solarização por 6 a 8 semanas na cultura do tomate apresentou mortalidade $99 \%$ de ovos e juvenis de M. incognita. Redução significativa no número de juvenis de $M$. incognita devido à solarização também foi observada por Baptista et al. (2004) nas camadas de $0-20 \mathrm{~cm}$ e $20-40 \mathrm{~cm}$. Uma provável explicação para a redução da população de nematóides no solo pela adição de matéria orgânica é a liberação de compostos tóxicos durante a decomposição da matéria orgânica e o favorecimento de populações de inimigos naturais (Rodríguez-Kábana, 1986; Ricci et al., 2000).

A massa da matéria fresca de raízes não foi influenciada pelos tratamentos de adubação ou pela solarização (Tabela 3). Contudo, foi observada interação entre adubação e solarização para a massa da matéria fresca da parte aérea, havendo influência dos tratamentos de adubação apenas no experimento sem solarização, com menor produtividade 
nos tratamentos de adubação orgânica e na testemunha (Tabela 3). As adubações não influenciaram a produção de matéria fresca da parte aérea no experimento com solarização; porém, a testemunha solarizada produziu mais que a testemunha não solarizada e tanto quanto os tratamentos adubados (Tabela 3). Barros et al. (2004) detectaram aumento da massa fresca de plantas de alface em solo solarizado, sendo o mesmo também relatado por Hasing et al. (2004). Marenco \& Lustosa (2000) observaram que a solarização do solo por nove semanas aumentou o rendimento da cenoura. Baptista et al. (2004) verificaram maior massa fresca da parte aérea nas plantas de tomate cultivadas em solo solarizado.

A maior produção na testemunha aqui relatada pode ser atribuída à solarização, uma vez que esse método pode favorecer a liberação de maior quantidade de nutrientes no solo e aumentar o rendimento das culturas (Ghini et al., 2003; Barros et al., 2004), como já foi observado na produção de cenoura, repolho, beterraba e vagem-anã em solo solarizado em cultivo orgânico (Ricci et al., 2000).

Observou-se correlações positivas e significativas para o número de massas de ovos e número de galhas, com coeficientes de 0,99 e 0,91 ( $\mathrm{P}<0,01)$, respectivamente, para o experimento com solarização e sem solarização, concordando com o fato de que essas variáveis apresentaram comportamento semelhante. Também foi verificada correlação positiva e significativa de 0,50 (P < 0,05 ) para a massa da matéria fresca da parte aérea e número de massas de ovos apenas para o experimento sem solarização. Provavelmente, essa correlação ocorreu pelo fato das plantas estarem bem nutridas, o que possibiltou suportar altas populações de nematóides em suas raízes, sem que houvesse redução na produção, principalmente nos tratamentos com adubação N-NH $\mathrm{N}_{4}, \mathrm{NPK}$ e orgânica mais NPK (Tabela 3), embora o número de massas de ovos tenha sido mais elevado na maioria dos tratamentos, concordando com Sharma et al. (2000). Essa correlação foi baixa no experimento com solarização, que reduziu a população de nematóides em praticamente todos os tratamentos.

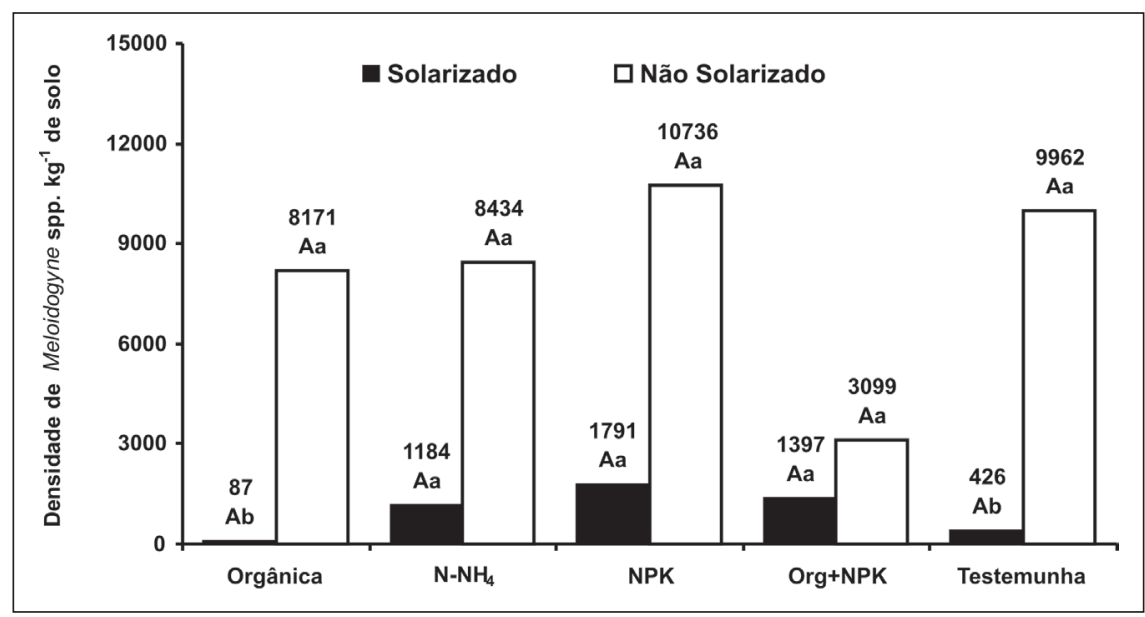

Figura 1. População final de Meloidogyne spp. na colheita da alface, nas condições solarizado e não solarizado em cada adubação. Letras maiúsculas comparam tratamentos de adubação dentro de cada experimento e letras minúsculas comparam experimentos, dentro de um mesmo tratamento de adubação, pelo teste de Scott-Knot (5\%). Dados transformados em $\log (\mathrm{x}+1)$ para análise de variância. Brasília, UnB-FAV, 2005.

A solarização combinada à adubações

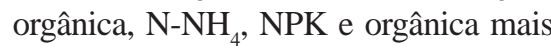
NPK reduziu de maneira eficiente o número de galhas e número de massas de ovos, sendo que a população de nematóides fitoparasitas, em especial Meloidogyne spp. nas raízes de alface da cultivar Verônica foi significativamente reduzida pela adubação orgânica combinada à solarização em cultivo protegido. A solarização apresenta-se como uma alternativa viável para o controle desses fitopatógenos, podendo contribuir para a redução do uso de agrotóxicos.

\section{AGRADECIMENTOS}

À Coordenação de Aperfeiçoamento de Pessoal de Nível Superior CAPES, pela concessão de bolsa de mestrado à primeira autora.

\section{REFERÊNCIAS}

BAPTISTA MJ; SOUZA RB; CARRIJO OA; VIDAL MC; CARCHAR JM. 2004 Solarização e biofumigação como alternativas para o controle de Meloidogyne incognita no cultivo protegido de tomate. Horticultura Brasileira 22: Supl. 02 (CD-ROM)

BAPTISTA MJ; SOUZA RB; PEREIRA W; CARRIJO OA; VIDAL MC; CARCHAR JM. 2006. Solarização do solo e biofumigação no cultivo protegido de tomate. Horticultura Brasileira 24: 1 .

BARROS BC; PATRÍCIO FRA; LOPES MEBM; FREITAS SS; SINIGAGLIA C; MALAVOLTA VMA; TESSARIOLI NETO J; GHINI R. 2004. Solarização do solo com filmes plásticos com e sem aditivo estabilizador de luz ultravioleta. Horticultura Brasileira 22: 2.
BETTIOL W; GHINI R; CUNHA MIB; TRATCH R; GALVÃO JAH. 1996. Solarização do solo para o controle de nematóide das galhas em quiabeiro. Horticultura Brasileira 14: 2.

CAMPOS H. 1984. Estatística aplicada à experimentação com cana-de-açúcar. São Paulo: FEALQ. 292p.

COOLEN W A. 1979. Methods for the extraction of Meloidogyne spp. and other nematodes from roots and soil. In: LAMBERTI F; TAYLOR $\mathrm{CE}$ (eds). 'Root-knot nematodes (Meloidogyne species): systematics, biology and control. London: Academic Press. p. 317-329.

FREITAS LG; MITCHELL DJ; DICKSON DW; CHELLEMI DO. 2000. Soil solarization and organic ammendment effects on Pasteuria penetrans. Nematologia Brasileira 24: 133146.

GHINI R; PATRICIO FRA; SOUZA MD; SINIGAGLIA C; BARROS BC; LOPES MEBM; TESSARIOLI NETO J; CANTARELLAH. 2003. Efeito da solarização sobre propriedades físicas, químicas e biológicas de solos. Revista Brasileira de Ciência do Solo 27: 71-79.

GHINI R. 2004. Solarização: histórico, resultados recentes e perspectivas. Summa Phytopathologica 30: 139-140.

GRECO N; BRANDONISIO A; ELIA F. 1992. Efficacy of SIP5561 and soil solarization for management of Meloidogyne incognita and $M$. javanica on tomato. Nematologia Mediterranea 20: 13-16.

HARTMAN KM; SASSER JN. 1985. Identification of Meloidogyne species on the basis of differential host test and perineal pattern morphology. In: BARKE KR; CARTER CC; SASSER JN (eds). An advanced treatise on Meloidogyne. Vol.2. North Carolina State: University Graphics, Raleigh. p. 69-77.

HASING JE; MOTSENBOCKER CE; MONLEZUN CJ. 2004. Agroeconomic effect of soil solarization on fall-planted lettuce (Lactuca sativa). Scientia Horticulturae 101: 223-233. 
JUNQUEIRA AMR; OLIVEIRA AT; ARAÚJO FC; MATTOS JKA. 2000. Eficiência da técnica de solarização na redução da infecção radicular por nematóides em alface. Horticultura Brasileira 18: 409-410.

LEFÈVRE AFV; SOUZA NL. 1993. Efeitos da solarização sobre algumas variáveis do solo. Summa Phytopathologica 19: 113-118.

MAGURRANAE. 1988. Ecological diversity and its measurements. Cambridge: University Press. 179p.

MARENCO R; LUSTOSA DC. 2000. Soil solarization for weed control in carrot. Pesquisa Agropecuária Brasileira 35: 2025-2032.

NETSCHER C; SIKORA A. 1990. Nematodes parasite of vegetables in: LUC MR; SIKORA A; BRIDGE J (eds). Plant parasitic nematodes in subtropical and tropical agriculture. Wallingford: CAB International Institute of Parasitology, 1990. p. 237-283.

OSTREC L; GRUBISIC D. 2003. Effects of soil solarization on nematodes in Croatia. Journal of Pest Science 76: 139-144.
RIBEIRO RCF; MIZOBUTSI EH; SILVA DG; PEREIRA JCR; ZAMBOLIM L. 1998. Controle de Meloidogyne javanica em alface por meio de compostos orgânicos. Fitopatologia Brasileira 23: 42-44.

RICCI MSF; ALMEIDA DL; FERNANDES MCA; RIBEIRO RLD; CATANHEIDE MCS. 2000. Efeitos da solarização do solo na densidade populacional da tiririca e na produtividade de hortaliças sob manejo orgânico. Pesquisa agropecuária Brasileira 35: 2175-2179.

RODRÍGUEZ-KÁBANA R. 1986. Organic and inorganic nitrogen amendments to soil as nematode suppressants. Journal of Nematology 18: 129-135.

SHARMA RD. 1985. Comparação de métodos para coletar ovos de Meloidogyne spp. de raízes, incluindo uma nova técnica. Nematologia Brasileira 9: 18-19.

SHARMA RD; SILVA JE; RESCK DVS; GOMES AC. 2000. Dinâmica de população de fitonematóides em solo tratado com lodo de esgoto em cultivos de milho. Nematologia Brasileira 24: 37-40.
SOUZA NL. 2004. Interação entre solarização e incorporação prévia de matéria orgânica no solo. Summa Phytopathologica 30: 142-143.

STAPLETON JJ; DEVAY JE. 1986. Soil solarization: non-chemical approach for management of plant pathogens and pests. Crop Protection 5: 190-198.

STAPLETON JJ. 2000. Soil solarization in various agricultural production systems. Crop Protection Surrey 19: 837-841.

TAYLOR AL; SASSER JN. 1978. Biology, identification and control of root-knot nematodes (Meloidogyne sp.). Raleigh: North Carolina State University, Graphics.111p.

TIHOHOD D. 1993. Nematologia agrícola aplicada. Jaboticabal: FUNEP. 372p.

VIDA JB; ZAMBOLIM L; TESSMANN DJ; BRANDÃO FILHO JUT; VERZIGNASSI JR; CAIXETA MP. 2004. Manejo de doenças de plantas em cultivo protegido. Fitopatologia Brasileira 29: 355-372. 